\title{
Developing and Validating an Age-Independent Equation Using Multi-Frequency Bioelectrical Impedance Analysis for Estimation of Appendicular Skeletal Muscle Mass and Establishing a Cutoff for Sarcopenia
}

\author{
Yosuke Yamada ${ }^{1, *}$ (D), Miyuki Nishizawa ${ }^{2}$, Tomoka Uchiyama ${ }^{2}$, Yasuhiro Kasahara ${ }^{2}$, \\ Mikio Shindo ${ }^{2}$, Motohiko Miyachi ${ }^{3}$ (D) and Shigeho Tanaka ${ }^{1}$ \\ 1 Department of Nutrition and Metabolism, National Institute of Health and Nutrition, \\ National Institutes of Biomedical Innovation, Health and Nutrition, 1-23-1 Toyama, Shinjuku-ku, \\ Tokyo 162-8636, Japan; tanakas@nibiohn.go.jp \\ 2 TANITA Body Weight Scientific Institute, TANITA Corporation, 1-14-2 Maeno, Itabashi-ku, \\ Tokyo 174-8630, Japan; miyuki.kodama.p@tanita.co.jp (M.N.); tomoka.uchiyama@tanita.co.jp (T.U.); \\ kasayasu@tanita.co.jp (Y.K.); mikio.shindo@tanita.co.jp (M.S.) \\ 3 Department of Physical Activity Research, National Institute of Health and Nutrition, \\ National Institutes of Biomedical Innovation, Health and Nutrition, 1-23-1 Toyama, Shinjuku-ku, \\ Tokyo 162-8636, Japan; miyachi@nibiohn.go.jp \\ * Correspondence: yamaday@nibiohn.go.jp; Tel.: +81-3-3203-5725
}

Received: 26 June 2017; Accepted: 15 July 2017; Published: 19 July 2017

\begin{abstract}
Background: Appendicular skeletal muscle (or lean) mass (ALM) estimated using dual-energy X-ray absorptiometry (DXA) is considered to be a preferred method for sarcopenia studies. However, DXA is expensive, has limited portability, and requires radiation exposure. Bioelectrical impedance analysis (BIA) is inexpensive, easy to use, and portable; thus BIA might be useful in sarcopenia investigations. However, a large variety of models have been commercially supplied by different companies, and for most consumer products, the equations estimating ALM are not disclosed. It is therefore difficult to use these equations for research purposes. In particular, the BIA equation is often age-dependent, which leads to fundamental difficulty in examining age-related ALM loss. The aims of the current study were as follows: (1) to develop and validate an equation to estimate ALM using multi-frequency BIA (MF-BIA) based on theoretical models, and (2) to establish sarcopenia cutoff values using the equation for the Japanese population. Methods: We measured height $(\mathrm{Ht})$, weight, and ALM obtained using DXA and a standing-posture 8-electrode MF-BIA $(5,50,250 \mathrm{kHz})$ in 756 Japanese individuals aged 18 to 86-years-old (222 men and 301 women as developing equation group and 97 men and 136 women as a cross validation group). The traditional impedance index $\left(\mathrm{Ht}^{2} / \mathrm{Z}_{50}\right)$ and impedance ratio of high and low frequency $\left(\mathrm{Z}_{250} / \mathrm{Z}_{5}\right)$ of hand to foot values were calculated. Multiple regression analyses were conducted with ALM as dependent variable in men and women separately. Results: We created the following equations: ALM $=(0.6947$ $\left.\times\left(\mathrm{Ht}^{2} / \mathrm{Z}_{50}\right)\right)+\left(-55.24 \times\left(\mathrm{Z}_{250} / \mathrm{Z}_{5}\right)\right)+\left(-10,940 \times\left(1 / \mathrm{Z}_{50}\right)\right)+51.33$ for men, and ALM $=(0.6144$ $\left.\times\left(\mathrm{Ht}^{2} / \mathrm{Z}_{50}\right)\right)+\left(-36.61 \times\left(\mathrm{Z}_{250} / \mathrm{Z}_{5}\right)\right)+\left(-9332 \times\left(1 / \mathrm{Z}_{50}\right)\right)+37.91$ for women. Additionally, we conducted measurements in 1624 men and 1368 women aged 18 to 40 years to establish sarcopenia cutoff values in the Japanese population. The mean values minus 2 standard deviations of the skeletal muscle mass index (ALM/ $\left./ \mathrm{Ht}^{2}\right)$ in these participants were 6.8 and $5.7 \mathrm{~kg} / \mathrm{m}^{2}$ in men and women, respectively. Conclusions: The current study established and validated a theoretical and age-independent equation using MF-BIA to estimate ALM and provided reasonable sarcopenia cutoff values.
\end{abstract}


Keywords: age-related skeletal muscle loss; sarcopenia; malnutrition risk assessment; DXA; multi-frequency BIA; aging

\section{Introduction}

Life span has dramatically increased worldwide [1], and it is projected that the population of older adults aged 65 and over will be approximately $40 \%$ in 2055 in Japan [2]. The incidence and prevalence of many diseases, such as metabolic dysfunction, mobility disorders, and frailty increase with ageing [3], and thus, aging of the population leads to increased medical and long-term care costs. Skeletal muscle is the largest organ in the body, and maintenance of its quality and mass is essential for the prevention of age-related decline in metabolic function and physical frailty [4,5].

Recently, several international working groups established diagnosis or screening cutoff values for sarcopenia, i.e., age-related muscle mass loss and loss of muscle strength and/or physical function [6-9]. The prevention or improvement of sarcopenia is the target of nutrition and/or exercise interventions in aging. In the diagnosis and screening of sarcopenia, the primary measurement used is skeletal muscle mass (SMM). According to the European Working Group on Sarcopenia in Older People (EWGSOP), X-ray computed tomography (CT) and magnetic resonance imaging (MRI) are gold standards for estimating SMM, and appendicular lean mass (ALM) measured by dual-energy X-ray absorptiometry (DXA) is considered to be an alternative preferred method and index for research and clinical use [7]. However, these methods are expensive, have limited portability, and with the exception of MRI, require radiation exposure. They are thus limited to use in routine health examinations.

Bioelectrical impedance analysis (BIA) is inexpensive, easy to use, portable, and requires no radiation exposure [10-24]. Thus, BIA may be useful as a portable alternative to DXA [25-29]. However, a large variety of models have been commercially supplied by different companies, and for most consumer products, the equations used to estimate ALM or SMM are not disclosed, making them difficult to use for research purposes [25]. In particular, the BIA equations are often age-dependent [30], which leads to fundamental difficulty in diagnosing age-related ALM loss. The aims of the current study were as follows: (1) to develop and validate an age-independent equation for estimation of ALM using multi-frequency BIA (MF-BIA) based on theoretical models, and (2) to establish cutoff values for sarcopenia using the equation for the Japanese population.

Skeletal muscle holds a large volume of water [31] and the water in skeletal muscle is distributed to both extra- and intracellular compartments (ECW and ICW, respectively) partitioned by muscle cell membranes [32]. Previous studies indicated that a relative expansion of ECW against ICW is observed in skeletal muscles with aging [32-34]. In addition, increased edema would influence the estimation of SMM by BIA [35-37]. Our hypothesis is that if we consider the effect of water distribution and the possibility of edema in the estimation model, theoretically, we can develop an age-independent equation based on MF-BIA for estimation of ALM.

\section{Materials and Methods}

\subsection{Participants}

For developing the equation and examining its validity, a total of 756 Japanese individuals who were undergoing a company health examination aged 18 to 86 years (222 men and 301 women as the developing equation group and 97 men and 136 women as the cross validation group) were enrolled in this study. The study protocol was approved by the ethics committee of the company, TANITA Co. IRB, and the approval numbers were \#004, 005, 010 and 012. All participants gave written informed consent after reviewing the purpose, methods, and significance of the study. We measured height $(\mathrm{Ht})$, weight, DXA, and MF-BIA. Additionally, we measured MF-BIA of 1624 men and 1368 women aged 18 to 40 years to establish a sarcopenia cutoff value for the Japanese population. Inclusion criteria were 
as follows: (1) reported ability to walk more than $10 \mathrm{~m}$ with or without a cane; (2) ability to provide informed consent with no indication of dementia; (3) no history of joint arthroplasty or current use of an artificial pacemaker.

\subsection{Multi-Frequency Bioelectrical Impedance Analysis}

A standing-posture 8-electrode MF-BIA (MC-780A-N, TANITA, Tokyo, Japan) was used to measure bioelectrical impedance $(Z)$ at 5,50 and $250 \mathrm{kHz}$ frequency $\left(Z_{5}, Z_{50}\right.$, and $Z_{250}$, respectively). Routine quality assurance procedures were conducted using a custom-made impedance tester and no instrument drift or shift was detected during the measurement period. Participants were evaluated in their underwear, in a standing position, and were asked to stand barefoot on toe-and heel electrodes and to hold the handgrips with arms hanging down a few centimeters from the hip. The eight-electrode method enables segmental impedance measurement. The electrical current is $\leq 90 \mu \mathrm{A}$. Minimum weight graduation was $0.1 \mathrm{~kg}$. Participants were instructed to refrain from vigorous exercise and consuming alcohol for the 24-h period before the experiment, to finish the last meal at least 2.5-h before the measurement, and to empty their bladder before the measurement. Measurements were conducted between 15:00 to 17:30, and room temperature was adjusted to maintain a thermoneutral environment.

Most BIA devices and equations use an impedance index $\left(\mathrm{Ht}^{2} / \mathrm{Z}_{50}\right)$ or resistance index of $50 \mathrm{kHz}$ $\left(\mathrm{Ht}^{2} / \mathrm{R}_{50}\right)$ calculated by $\mathrm{Ht}$ and $\mathrm{Z}_{50}$ or resistance at $50 \mathrm{kHz}\left(\mathrm{R}_{50}\right)$ as a predicting variable for $\mathrm{AMM}$ or ALM $[17,30,38]$. In the human body, reactance is less than $10 \%$ of resistance, and correlation between impedance and resistance are $>0.99$; thus $\mathrm{Ht}^{2} / \mathrm{Z}_{50}$ and $\mathrm{Ht}^{2} / \mathrm{R}_{50}$ are interchangeable. We chose to use $\mathrm{Ht}^{2} / \mathrm{Z}_{50}$ as a candidate independent variable to estimate ALM in this study. One of the most well-known equations for estimating muscle mass by BIA was developed by Janssen et al. using MRI as follows: $\mathrm{SMM}(\mathrm{kg})=\left(\left(\mathrm{Ht}^{2} / \mathrm{R}_{50} \times 0.401\right)+(\operatorname{sex} \times 3.825)+(\right.$ age $\left.\times-0.071)\right)+5.102$ [30], and many BIA equations are age-dependent. Yamada et al. indicated that expansion of ECW relative to ICW or total body water (TBW) is observed with aging, and may mask actual age-related decrease of muscle cell mass [32,34,39-41]. The $Z$ at low-frequency $\left(\leq 50 \mathrm{kHz}\right.$, for example, $Z_{5}$ or $Z_{50}$ ) currents mainly reflects ECW. In contrast, the $Z$ at high-frequency $(\geq 250 \mathrm{kHz})$ reflects TBW. Thus, the impedance ratio of $Z_{250}$ against $Z_{5}\left(Z_{250} / Z_{5}\right)$ is an index of ECW/TBW, and we chose to use $Z_{250} / Z_{5}$ as another candidate independent variable to estimate ALM. In addition, the possibility of edema affects ALM estimation, i.e., if the person has edema, particularly peripheral edema, the BIA overestimates actual ALM. The index of $1 / Z_{5}$ or $1 / Z_{50}$ could potentially be applied as an adjusting variable for this situation. Thus, we selected $1 / Z_{50}$ as an additional candidate independent variable to estimate ALM. We developed estimating equations for men and women separately, because body composition and fat and muscle distribution are quite different between men and women.

\subsection{Dual-Energy X-ray Absorptiometry}

A Lunar DPX-L (GE Healthcare, Madison, WI, USA) densitometer was used and analyses were performed using the software version of 1.35 (Lunar DPX-L ver1.35, GE Healthcare Lunar, Madison, WI, USA) to obtain ALM. Routine densitometry quality assurance procedures were conducted using a standard phantom once per week and calibrated before the test, and no instrument drift or shift was detected during the measurement period.

\subsection{Statistical Analysis}

Results are presented as means \pm standard deviations (SD) with maximum and minimum values. As the physical characteristics were different between sexes, the statistical analyses were applied to men and women separately. To examine the association between age and other variables, quadratic regression analyses were conducted with $\mathrm{ALM}, \mathrm{Ht}^{2} / \mathrm{Z}_{50}$, and $\mathrm{Z}_{250} / \mathrm{Z}_{5}$ against age, and determination coefficients were obtained. To examine the effect of age on BIA estimation, we investigated the association between age and the residual of the ALM obtained by DXA and the ALM estimated by one 
of the previous BIA equations for Japanese older adults aged 65 years and over using TANITA BIA according to the following Equations [38]:

$$
\begin{gathered}
\text { Men: } \mathrm{ALM}=\left(0.197 \times\left(\mathrm{Ht}^{2} / \mathrm{Z}_{50}\right)\right)+(0.179 \times \text { Weight })-0.019 \\
\text { Women: } \mathrm{ALM}=\left(0.221 \times\left(\mathrm{Ht}^{2} / \mathrm{Z}_{50}\right)\right)+(0.117 \times \text { Weight })+0.881
\end{gathered}
$$

Multiple linear regression analyses were conducted for the equation developing groups using $\mathrm{Ht}^{2} / \mathrm{Z}_{50}, \mathrm{Z}_{250} / \mathrm{Z}_{5}$, and $1 / \mathrm{Z}_{50}$ as independent variables and ALM as the dependent variable, where entry probability of $F$ was 0.05 and removal was 0.10 . To validate the newly developed equation, the association between the ALM estimated with the newly developed MF-BIA equation and the ALM obtained by DXA was examined in the validation groups and pair t-test was conducted between measured and estimated ALM. To establish sarcopenia cutoff values based on Baumgartner et al. [42], we calculated the mean minus 2SD in 1624 men and 1368 women aged 18 to 40 years using the equation. All analyses were performed using SPSS software (Version 22.0 for Windows, IBM Corp., Armonk, NY, USA). For all analyses, $p<0.05$ was used to indicate statistical significance.

\section{Results}

The physical characteristics and BIA variables of study participants are presented in Table 1. Height, weight, body mass index (BMI), ALM, $Z_{5}, Z_{50}, Z_{250}, \mathrm{Ht}^{2} / Z_{50}, Z_{250} / Z_{5}$ and $1 / Z_{50}$ were significantly different between men and women.

\begin{tabular}{|c|c|c|c|c|c|c|}
\hline & \multicolumn{3}{|c|}{ Equation Developing Group (222 Men) } & \multicolumn{3}{|c|}{ Validation Group (97 Men) } \\
\hline & Mean \pm SD & MAX & MIN & Mean \pm SD & MAX & MIN \\
\hline Age & $46 \pm 17$ & 81 & 18 & $49 \pm 18$ & 78 & 18 \\
\hline $\mathrm{Ht}$ & $167.5 \pm 6.8$ & 181.9 & 147.1 & $167.0 \pm 7.6$ & 184.6 & 150.0 \\
\hline Wt & $64.8 \pm 9.5$ & 93.3 & 45.4 & $67.0 \pm 10.4$ & 99.0 & 47.3 \\
\hline BMI & $23.1 \pm 2.8$ & 31.5 & 16.2 & $24.0 \pm 3.1$ & 31.1 & 17.6 \\
\hline $\mathrm{ALM}_{\mathrm{DXA}}$ & $23.5 \pm 3.8$ & 32.3 & 14.8 & $23.8 \pm 4.2$ & 34.5 & 16.0 \\
\hline $\mathrm{Z}_{5}$ & $655.2 \pm 64.8$ & 837.2 & 498.7 & $636.4 \pm 62.5$ & 811.1 & 499.4 \\
\hline$Z_{50}$ & $573.6 \pm 58.0$ & 735.6 & 437.2 & $557.0 \pm 56.5$ & 719.7 & 442.1 \\
\hline$Z_{250}$ & $508.6 \pm 52.6$ & 657.2 & 388.6 & $494.5 \pm 50.3$ & 641.4 & 391.3 \\
\hline $\mathrm{Ht}^{2} / \mathrm{Z}_{50}$ & $49.5 \pm 5.8$ & 66.9 & 33.1 & $50.6 \pm 6.5$ & 72.4 & 34.5 \\
\hline $\mathrm{Z}_{250} / \mathrm{Z}_{5}$ & $0.776 \pm 0.020$ & 0.838 & 0.724 & $0.777 \pm 0.020$ & 0.830 & 0.736 \\
\hline \multirow[t]{3}{*}{$1 / Z_{50}$} & $0.00176 \pm 0.00018$ & 0.00229 & 0.00136 & $0.00181 \pm 0.00018$ & 0.00226 & 0.00139 \\
\hline & \multicolumn{3}{|c|}{ Equation Developing Group (301 Women) } & \multicolumn{3}{|c|}{ Validation Group (136 Women) } \\
\hline & Mean \pm SD & MAX & MIN & Mean \pm SD & MAX & MIN \\
\hline Age & $47 \pm 18$ & 86 & 18 & $44 \pm 18$ & 85 & 18 \\
\hline $\mathrm{Ht}$ & $154.7 \pm 6.7$ & 172.4 & 137.3 & $155.2 \pm 7.1$ & 170.2 & 138.3 \\
\hline $\mathrm{Wt}$ & $54.0 \pm 7.3$ & 83.6 & 38.3 & $54.1 \pm 8.3$ & 80.4 & 32.5 \\
\hline BMI & $22.6 \pm 3.1$ & 33.7 & 16.6 & $22.4 \pm 3.0$ & 32.9 & 16.0 \\
\hline $\mathrm{ALM}_{\mathrm{DXA}}$ & $16.5 \pm 2.5$ & 24.2 & 10.8 & $17.0 \pm 3.1$ & 28.2 & 10.4 \\
\hline $\mathrm{Z}_{5}$ & $730.8 \pm 81.2$ & 965.4 & 536.9 & $736.7 \pm 79.9$ & 995.7 & 508.5 \\
\hline$Z_{50}$ & $657.9 \pm 73.0$ & 885.1 & 484.3 & $661.1 \pm 72.6$ & 901.1 & 464.6 \\
\hline$Z_{250}$ & $591.0 \pm 65.7$ & 799.5 & 438.7 & $592.7 \pm 66.0$ & 815.0 & 420.1 \\
\hline $\mathrm{Ht}^{2} / \mathrm{Z}_{50}$ & $36.8 \pm 4.2$ & 49.8 & 27.1 & $36.9 \pm 5.2$ & 52.1 & 24.3 \\
\hline$Z_{250} / Z_{5}$ & $0.809 \pm 0.018$ & 0.861 & 0.746 & $0.805 \pm 0.020$ & 0.851 & 0.742 \\
\hline $1 / Z_{50}$ & $0.00154 \pm 0.00017$ & 0.00206 & 0.00113 & $0.00153 \pm 0.00017$ & 0.00215 & 0.00111 \\
\hline
\end{tabular}

Table 1. Physical characteristics and BIA variables of participants for equation developing and validation.

Ht, height; Wt, weight; BMI, body mass index; $\mathrm{ALM}_{\mathrm{DX} A}$, appendicular lean mass by dual X-ray absorptiometry; $\mathrm{Z}_{5}$,

$Z_{50}$, and $Z_{250}$, whole body impedance of 5, 50, and $250 \mathrm{kHz}$.

Figure $1 \mathrm{~A}, \mathrm{~B}$ shows the association between the ALM estimated by the previous BIA equation (see methods section) and the ALM obtained by DXA. The determinant coefficients were just moderate $\left(R^{2}=0.49\right.$ and 0.44 for men and women, respectively). Figure 1C,D shows the correlation between age and the residual of the ALM obtained by DXA and the ALM estimated by the previous BIA equation. The residual significantly correlated with age, and the previous BIA equation underestimated ALM in young adults. Thus, the previous equation cannot be used to examine age-related ALM loss. 
(A)$$
\text { (C) }
$$
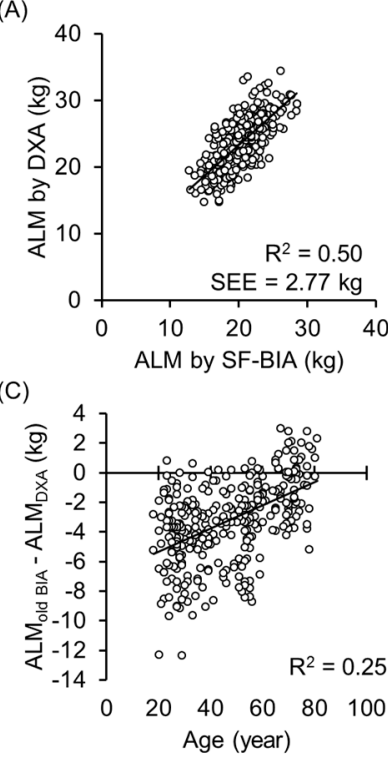

(B)

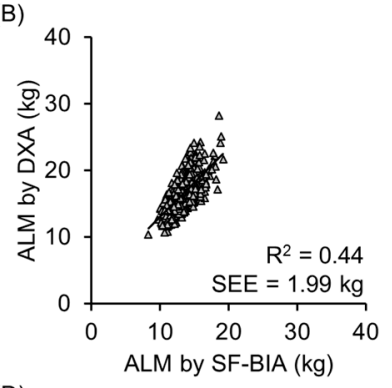

(D)

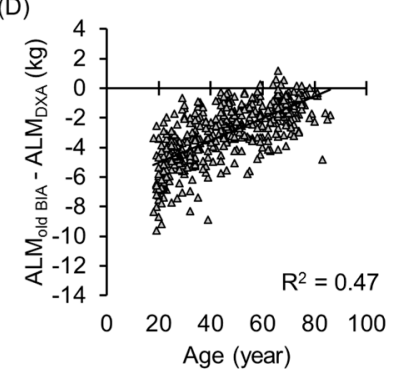

Figure 1. A and B shows the relationship between the appendicular lean mass (ALM) estimated by one of the previous bioelectrical impedance analysis equation for a standing-posture 8-electrode TANITA MF-BIA and the ALM obtained dual X-ray absorptiometry (DXA) in 319 men (A) and 437 women; (B) The equation was established and validated for Japanese older adults aged $65 \mathrm{y}$ and over as a previous equation by [38]. The determinant coefficient were just moderate $\left(R^{2}=0.50\right.$ and 0.44 , men and women, respectively) because of the wide range of the age in the current participants (18 to 86 years). (C,D) shows the relationship between age and the residual of the ALM obtained DXA and the ALM estimated by the previous BIA equation. The residual was significantly correlated with age, which indicated that the previous BIA equation underestimated ALM in young adults. The previous equation cannot be used to examine age-related ALM loss.

Figure 2 shows the association between age and the ALM obtained by DXA in 319 men (A) and 437 women (B). The determinant coefficients of quadratic regression analysis were $R^{2}=0.42$ and 0.29 in men and women, respectively. In contrast, as Figure 3 shows, the determinant coefficients of quadratic regression analysis between age and $\mathrm{Ht}^{2} / \mathrm{Z}_{50}$ obtained by BIA were $\mathrm{R}^{2}=0.11$ and 0.04 in men and women, respectively.

(A)

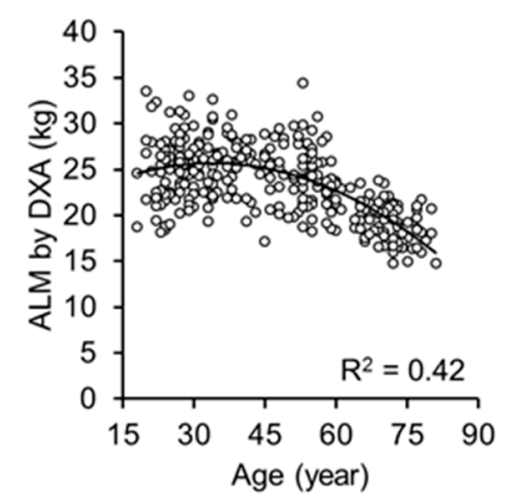

(B)

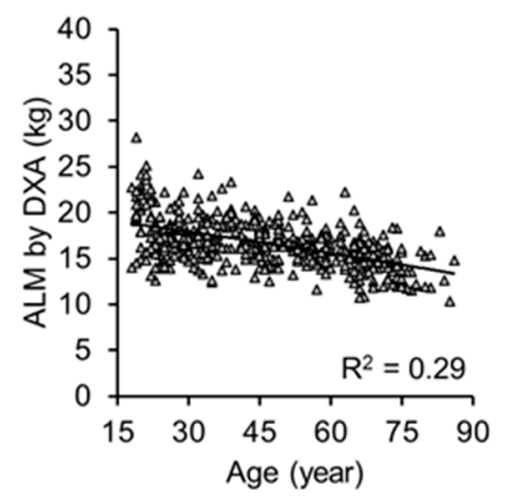

Figure 2. Relationship between age and the appendicular lean mass (ALM) obtained by DXA in 319 men (A) and 437 women (B) aged 18 to 86 years old. The determinant coefficients of quadratic regression analysis were $R^{2}=0.42$ and 0.29 , respectively. 
(A)

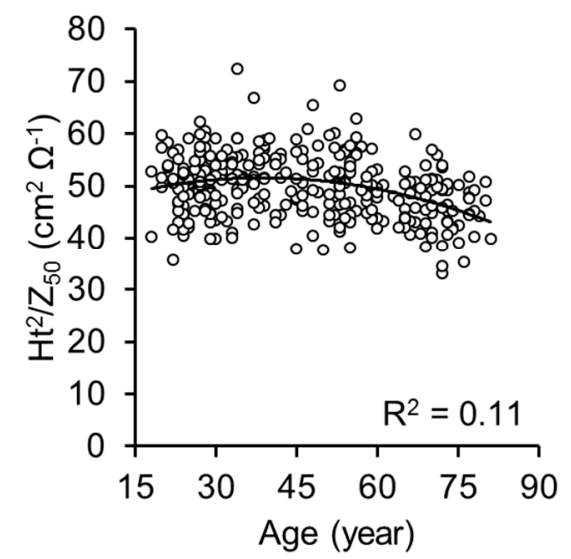

(B)

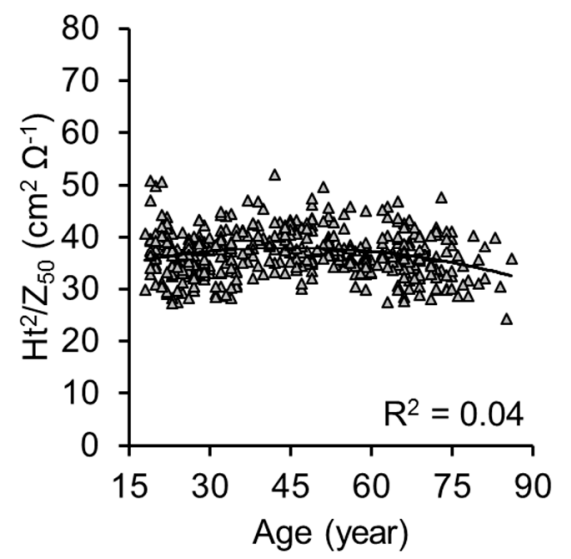

Figure 3. Relationship between age and the impedance index (height squired divided by impedance at $50 \mathrm{kHz}: \mathrm{Ht}^{2} / \mathrm{Z}_{50}$ ) obtained by bioelectrical impedance analysis in 319 men (A) and 437 women (B) aged 18 to 86 years old. The determinant coefficients of quadratic regression analysis were $\mathrm{R}^{2}=0.11$ and 0.04 , respectively, which is significantly lower than that of the age-ALM relationship in DXA.

Figure 4 shows the quadratic association between age and the index $\left(Z_{250} / Z_{5}\right)$ of the ratio between extra- to intra-cellular water compartments obtained by MF-BIA in men (A) and women (B). The determinant coefficients of quadratic regression analysis were $\mathrm{R}^{2}=0.37$ and 0.23 , respectively.

(A)

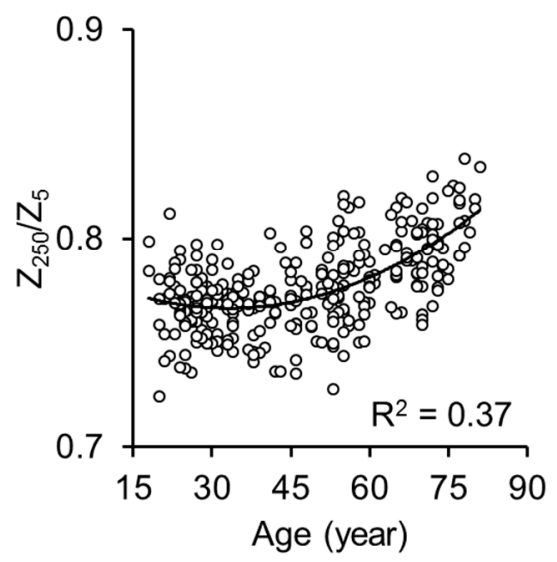

(B)

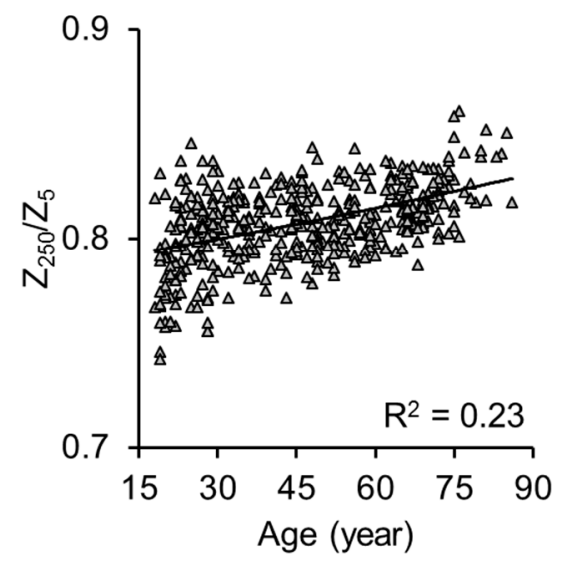

Figure 4. Relationship between age and the impedance ratio of high and low frequency (impedance at $250 \mathrm{kHz}$ divided by impedance at $5 \mathrm{kHz}: Z_{250} / Z_{5}$ ) obtained by multi-frequency bioelectrical impedance analysis (MF-BIA) in 319 men (A) and 437 women (B) aged 18 to 86 years old. The determinant coefficients of quadratic regression analysis were $R^{2}=0.37$ and 0.23 , respectively. The $Z_{250} / Z_{5}$ is the index of the ratio between extra- and intra-cellular water compartments in the body.

Table 2 shows the results of multivariate analysis of the linear model with ALM as a dependent model in the developing equation groups for men and women, respectively. In model $1, \mathrm{Ht}^{2} / \mathrm{Z}_{50}$ was a significant independent variable to estimate ALM, but the determinant coefficient was moderate and the standard error of estimation (SEE) was relatively large (2.27 and $1.88 \mathrm{~kg}$ in men and women, respectively). In contrast, in the final model (model 3), all impedance variables became significant independent variables to estimate ALM, the determinant coefficients became significantly greater than model 1, and SEE became lower than models 1 and 2 (1.46 and $1.22 \mathrm{~kg}$ in men and women, 
respectively). The variance inflation factor (VIF), an index to detect multicollinearity, was less than 5 , so that the final model is acceptable to use. The negative coefficients of $1 / Z_{50}$ indicated that $1 / Z_{50}$ did work as a suppressor variable in the model.

Table 2. Multivariate analysis: Linear model with ALM as a dependent variable.

\begin{tabular}{|c|c|c|c|c|c|}
\hline \multirow{2}{*}{\multicolumn{2}{|c|}{ Men $(n=222)$}} & \multicolumn{2}{|c|}{ Coefficients } & \multirow{3}{*}{$\begin{array}{l}\text { Sig. } \\
<0.001 \\
0.1401\end{array}$} & \multirow{3}{*}{ Collinearity VIF } \\
\hline & & \multirow{2}{*}{$\begin{array}{c}\text { Unstandardized } \\
\text { B } \\
0.5153 \\
-1.941\end{array}$} & \multirow{2}{*}{$\begin{array}{c}\begin{array}{c}\text { Standardized } \\
\text { Beta }\end{array} \\
0.797\end{array}$} & & \\
\hline 1 & $\begin{array}{l}\mathrm{Ht}^{2} / \mathrm{Z}_{50} \\
\text { (Constant) } \\
\mathrm{R}^{2}=0.635, \mathrm{SEE}=2.27 \mathrm{~kg}\end{array}$ & & & & \\
\hline 2 & $\begin{array}{l}\mathrm{Ht}^{2} / \mathrm{Z}_{50} \\
\mathrm{Z}_{250} / \mathrm{Z}_{5} \\
\text { (Constant) } \\
\mathrm{R}^{2}=0.735, \mathrm{SEE}=1.94 \mathrm{~kg}\end{array}$ & $\begin{array}{l}0.4396 \\
-62.84 \\
50.58\end{array}$ & $\begin{array}{c}0.680 \\
-0.337\end{array}$ & $\begin{array}{l}<0.001 \\
<0.001 \\
<0.001\end{array}$ & $\begin{array}{l}1.138 \\
1.138\end{array}$ \\
\hline 3 & $\begin{array}{l}\mathrm{Ht}^{2} / \mathrm{Z}_{50} \\
\mathrm{Z}_{250} / \mathrm{Z}_{5} \\
1 / \mathrm{Z}_{50} \\
\text { (Constant) } \\
\mathrm{R}^{2}=0.851, \mathrm{SEE}=1.46 \mathrm{~kg}\end{array}$ & $\begin{array}{c}0.6947 \\
-55.24 \\
-10941 \\
51.33\end{array}$ & $\begin{array}{c}1.075 \\
-0.296 \\
-0.513\end{array}$ & $\begin{array}{l}<0.001 \\
<0.001 \\
<0.001 \\
<0.001\end{array}$ & $\begin{array}{l}2.473 \\
1.152 \\
2.254\end{array}$ \\
\hline & $n(n=301)$ & B & Beta & & VIF \\
\hline 1 & $\begin{array}{l}\mathrm{Ht}^{2} / \mathrm{Z}_{50} \\
\text { (Constant) } \\
\mathrm{R}^{2}=0.415, \mathrm{SEE}=1.88 \mathrm{~kg}\end{array}$ & $\begin{array}{c}0.3797 \\
2.567\end{array}$ & 0.644 & $\begin{array}{c}<0.001 \\
0.008\end{array}$ & \\
\hline 2 & $\begin{array}{l}\mathrm{Ht}^{2} / \mathrm{Z}_{50} \\
\mathrm{Z}_{250} / \mathrm{Z}_{5} \\
\text { (Constant) } \\
\mathrm{R}^{2}=0.552, \mathrm{SEE}=1.65 \mathrm{~kg}\end{array}$ & $\begin{array}{c}0.3346 \\
-50.68 \\
45.22\end{array}$ & $\begin{array}{c}0.568 \\
-0.378\end{array}$ & $\begin{array}{l}<0.001 \\
<0.001 \\
<0.001\end{array}$ & $\begin{array}{l}1.043 \\
1.043\end{array}$ \\
\hline 3 & $\begin{array}{l}\mathrm{Ht}^{2} / \mathrm{Z}_{50} \\
\mathrm{Z}_{250} / \mathrm{Z}_{5} \\
1 / \mathrm{Z}_{50} \\
\text { (Constant) } \\
\mathrm{R}^{2}=0.757, \mathrm{SEE}=1.22 \mathrm{~kg}\end{array}$ & $\begin{array}{c}0.6144 \\
-36.61 \\
-9332 \\
37.91\end{array}$ & $\begin{array}{c}1.042 \\
-0.273 \\
-0.649\end{array}$ & $\begin{array}{l}<0.001 \\
<0.001 \\
<0.001 \\
<0.001\end{array}$ & $\begin{array}{c}2.14 \\
1.096 \\
2.053\end{array}$ \\
\hline
\end{tabular}

The final equations were following:

$$
\begin{aligned}
& \text { Men: } \mathrm{ALM}=\left(0.6947 \times\left(\mathrm{Ht}^{2} / \mathrm{Z}_{50}\right)\right)+\left(-55.24 \times\left(\mathrm{Z}_{250} / \mathrm{Z}_{5}\right)\right)+\left(-10940 \times\left(1 / \mathrm{Z}_{50}\right)\right)+51.33 \\
& \text { Women: } \mathrm{ALM}=\left(0.6144 \times\left(\mathrm{Ht}^{2} / \mathrm{Z}_{50}\right)\right)+\left(-36.61 \times\left(\mathrm{Z}_{250} / \mathrm{Z}_{5}\right)\right)+\left(-9332 \times\left(1 / \mathrm{Z}_{50}\right)\right)+37.91
\end{aligned}
$$

We applied the equations to the cross validation group (97 men and 136 women). Figure 5 shows the association between ALM estimated by the new equation using MF-BIA and ALM measured by DXA in the cross validation group. The determinant coefficients of linear regression analysis were $\mathrm{R}^{2}=0.87$ and 0.86 , respectively. The SEE was 1.53 and $1.15 \mathrm{~kg}$ in men and women, respectively. The intercept was not significantly different from zero and the slope was not significantly different from one $(p<0.05)$. There were no significant differences between measured and estimated ALM both in men $(p=0.57)$ and women $(p=0.24)$ by the paired $t$-test. We calculated the skeletal muscle index (SMI) as follows: $\mathrm{SMI}=\mathrm{ALM} / \mathrm{Ht}^{2}$, and the determinant coefficients of the association between SMI by DXA and SMI by MF-BIA in the validation group were $\mathrm{R}^{2}=0.69$ and 0.67 , in men and women, respectively. Figure 6 shows the correlation between age and ALM obtained by the new MF-BIA and the correlations with age were very similar to that of DXA (Figures 1 and 6). 


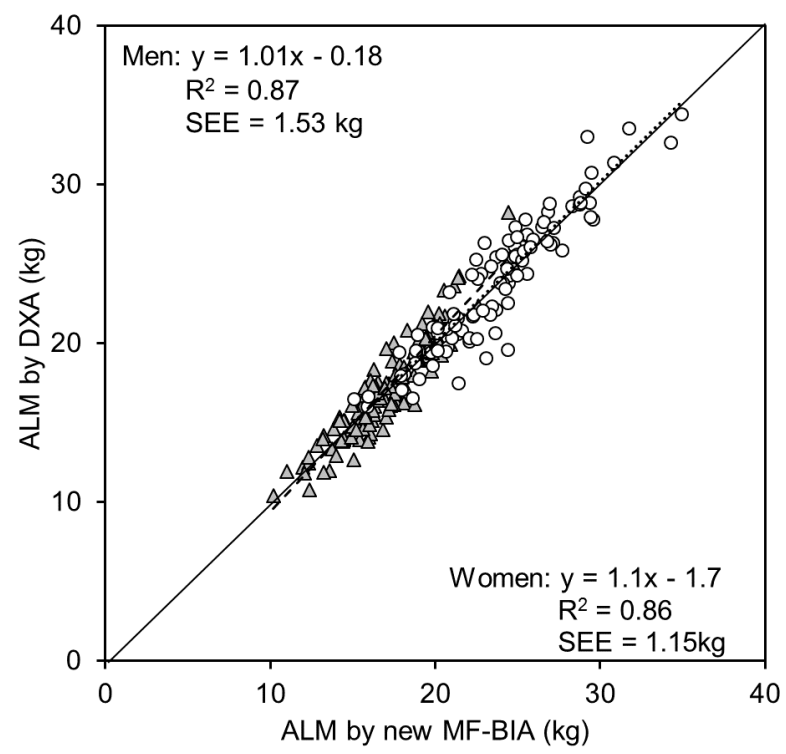

Figure 5. Relationship between ALM estimated by new equation of MF-BIA established with the developing group (222 men and 301 women) against ALM by DXA in validation group with 97 men and 136 women. The determinant coefficients of linear regression analysis were $R^{2}=0.87$ and 0.85 , respectively. The intercept was not significantly different from zero and the slope was not significantly different from one.

(A)

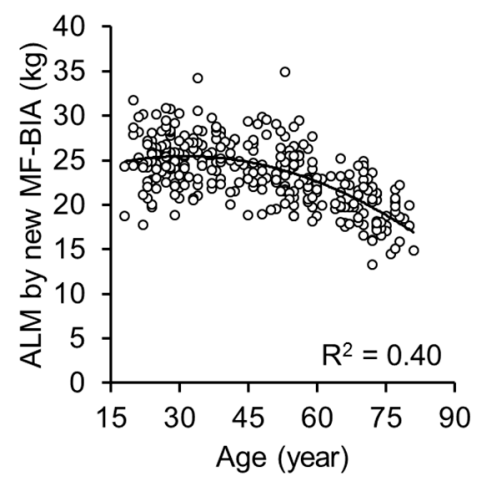

(B)

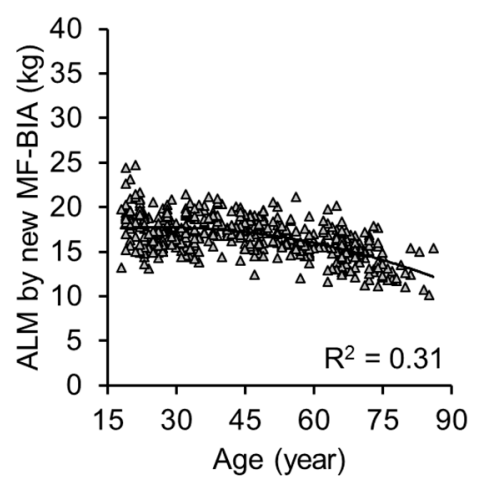

Figure 6. Relationship between age and ALM obtained by new MF-BIA in 319 men (A) and 437 women (B) aged 18 to 86 years old. The determinant coefficients of quadratic regression analysis were $\mathrm{R}^{2}=0.40$ and 0.31 , respectively.

Furthermore, we measured MF-BIA of 1624 men (mean \pm SD; height $171.5 \pm 5.8 \mathrm{~cm}$, weight $69.8 \pm 12.8 \mathrm{~kg}$, BMI $23.7 \pm 4.0)$ and 1368 women $(158.3 \pm 5.3 \mathrm{~cm}, 54.4 \pm 9.5 \mathrm{~kg}$, BMI $21.7 \pm 3.7)$ aged 18 to 40 years to establish sarcopenia cutoff values for the Japanese population. The estimated ALM was $25.1 \pm 3.3$ and $17.0 \pm 1.9 \mathrm{~kg}$ in men and women, respectively. The SMI were $8.5 \pm 0.8$ and $6.8 \pm 0.5 \mathrm{~kg} / \mathrm{m}^{2}$, and thus the sarcopenia cutoff values (mean minus 2SD) were 6.8 and $5.7 \mathrm{~kg} / \mathrm{m}^{2}$ in men and women, respectively.

\section{Discussion}

The aims of the preset study were: (1) to develop and validate an equation to estimate ALM using a standing-posture 8-electrode MF-BIA using theoretical age-independent models, and (2) to establish sarcopenia cutoff values (mean minus 2SD) using a large scale database of Japanese persons aged 18 to 40 years. We developed and validated an age-independent theoretical MF-BIA equation while 
totally disclosing the theoretical background and development process. The accuracy and precision of the established equation seems reasonable in spite of only using the impedance indices in the regression model.

There are many reports in the literature validating consumer or professional models of BIAs (single-frequency, multi-frequency, whole body or segmental measurements) [43,44]. However, approximately one-half of the papers examined the validity of the output value from BIA software in which the equations have not been disclosed. Thus, it is very difficult to discuss the etiology of the differences between BIA devices or software programs and/or the reasons for the validation results.

One previous study developed an equation and validated it for TANITA BIA in Japanese older adults aged 65 years and over. The equation was simple and used only $50 \mathrm{kHz}$ data, as follows: ALM $=\left(0.197 \times\left(\mathrm{Ht}^{2} / \mathrm{Z}_{50}\right)\right)+(0.179 \times$ Weight $)-0.019$ for men, and ALM $=\left(0.221 \times\left(\mathrm{Ht}^{2} / \mathrm{Z}_{50}\right)\right)+(0.117 \times$ Weight $)+0.881$ for women [38]. The impedance index $\left(\mathrm{Ht}^{2} / \mathrm{Z}_{50}\right)$ has been used for estimating ALM and/or SMM in many articles. However, when we applied this equation to individuals over a wide age range (18 to 86 years), the equation underestimated ALM significantly in the younger population. We examined the mechanism of this underestimation. The $\mathrm{Ht}^{2} / \mathrm{Z}_{50}$ did not seem to reflect age-related ALM decline, because $\mathrm{Ht}^{2} / \mathrm{Z}_{50}$ was not correlated with age $\left(\mathrm{R}^{2}=0.11\right.$ and 0.04 , in men and women, respectively) compared with DXA $\left(R^{2}=0.42\right.$ and 0.29 , in men and women, respectively), which led to age-related underestimation of the BIA.

To solve the problem, we introduced other variables-the impedance ratio of $Z_{250}$ against $Z_{5}$ $\left(Z_{250} / Z_{5}\right)$, an index of ECW/TBW. Previously, Yamada et al. [32,34,39-41] indicated that the impedance ratio of low to high frequency strongly correlated with age and muscle strength, and suggested that the impedance ratio is an important marker of muscle quality. They stated that the impedance ratio reflects the ratio of actual muscle cell mass against total body water. In the present study, $Z_{250} / Z_{5}$ correlated significantly with age $\left(R^{2}=0.37\right.$ and 0.23 in men and women, respectively). In the multiple regression model $2, Z_{250} / Z_{5}$ significantly improved the accuracy of ALM prediction, which means that it is essential to take into account the water distribution within the body to estimate ALM by BIA.

In addition, it is well known that BIA is affected by edema or inter-segmental water shift [35-37,45], particularly in peripheral segments, such as the ankle and wrist. If a person has edema, in particular peripheral edema, the BIA overestimates actual ALM. To solve this problem, previous studies have used proximal electrode placement locations, such as the knee and elbow. The proximal methods were effective for accurate estimation of body composition, but a major problem is that the proximal methods require additional adhesive-type electrodes on the knees and elbows. This takes time and increases costs, and requires experts who are familiar with anatomical landmarks. We, therefore, tried to solve the problem without using proximal electrode measurement methods. We hypothesized that the index of $1 / Z_{5}$ or $1 / Z_{50}$ may be applied as an adjusting variable in this situation. In the multiple regression model 3, $1 / Z_{50}$ significantly improved the accuracy of ALM prediction. This final model did not have multicollinearity (VIF < 2.5) and had high determinant coefficients. The coefficients of $1 / Z_{50}$ were negative, which means the variables work as a suppressor when an individual had possible edema or water shift into peripheral extra-water segments.

We validated the newly developed equation with the cross validation group, which was an independent group from the equation developing group. As Figure 4 shows, the determinant coefficients of linear regression analysis were very high with reasonable SEE values. The regression line was not significantly different from $Y=X$. The results indicate that the newly developed equation was cross validated.

The second aim of the current study was to establish a sarcopenia cutoff value using the new equation for the Japanese population. For this purpose, we measured MF-BIA of 1624 men and 1368 women aged 18 to 40 years. The estimated ALM was $25.1 \pm 3.3$ and $17.0 \pm 1.9 \mathrm{~kg}$ in men and women, respectively. The SMI values were $8.5 \pm 0.8$ and $6.8 \pm 0.5 \mathrm{~kg} / \mathrm{m}^{2}$, and thus the sarcopenia cutoff values (mean minus 2SD) based on Baumgartener et al. [42] were 6.8 and $5.7 \mathrm{~kg} / \mathrm{m}^{2}$ in men and women, respectively. For the Japanese population, Sanada et al. [46] established a cut off using 
DXA (QDR-4500A, Hologic, MA, USA) as 6.87 and $5.46 \mathrm{~kg} / \mathrm{m}^{2}$ in men and women, respectively. Tanimoto et al. [47] established a cut off using BIA (TANITA MC-190) of 7.0 and $5.8 \mathrm{~kg} / \mathrm{m}^{2}$ in men and women, respectively. Yoshida et al. [38] used a BIA (MC-190) and suggested cut offs of 7.09 and $5.91 \mathrm{~kg} / \mathrm{m}^{2}$ in men and women, respectively. Yamada et al. [48] established a cut off using a BIA (Inbody 720, Biospace) and reported values of 6.75 and $5.07 \mathrm{~kg} / \mathrm{m}^{2}$ in men and women, respectively. It is important to note that Yamada et al. [49] reported that if we used the manufacturer's own formula, which is undisclosed, different MF-BIA devices provided different SMI values, but if we used one disclosed equation, even with different devices, MF-BIAs provided the same SMI values over a wide age range (18 to 89 years). The sarcopenia cut off value established in the current study was very similar to the value from the previous publication using DXA [46], and within the range previously published in the literature. Thus, we consider that the values of 6.8 and $5.7 \mathrm{~kg} / \mathrm{m}^{2}$ from $1624 \mathrm{men}$ and 1368 women, aged 18 to 40 years, can be reasonably used as sarcopenia cut off levels for the Japanese population.

Some limitations of the current study should be noted. First, in previous literature reports, many researchers established and disclosed various equations using professional BIA devices for estimating body composition $[17,43]$. We did not examine these because there are too many published equations to examine them all, the majority of them are not designed for the Asian population, at least half of the equations include age, and these equations were developed against multiple different gold standards (MRI, CT, underwater weighting, stable isotope dilution, and DXA) for estimating different body composition parts. We cannot state the superiority of the current equation compared with previously established and disclosed equations, which was not the focus of the current analysis. Second, EWGSOP stated that CT and MRI are gold standards for estimating SMM, and ALM of DXA is considered to be an alternative preferred method [7]. However, whole body CT scan requires a high level of radiation exposure, and whole body MRI requires time-consuming post-scan image processing to obtain SMM; thus, we used ALM derived from DXA as the reference. Theoretically, ALM of DXA reflects whole lean tissue mass and is not perfectly equal to SMM. In addition, muscle quality and muscle composition change with aging [50-57], but the current study does not examine these effect. As another limitation, Prado et al. [58] stated that a single cutoff may not suitable for all ages; they used a large dataset of DXA ALM with 13,236 individuals from the 1999 to 2004 NHANES cohort and LMS curve-fitting procedure to establish age and gender specific cutoffs. Our current sample size is much lower than the previous study, thus we need collect more data to develop age and gender specific cut offs based on the LMS method. Further research is needed. Strengths of this study include the adequate sample size to develop and validate a new equation and establish sarcopenia cut off values, and the theoretical equation development in the present study.

\section{Conclusions}

In conclusion, we established an age-independent MF-BIA equation for the Japanese population as follows: $\mathrm{ALM}=\left(0.6947 \times\left(\mathrm{Ht}^{2} / \mathrm{Z}_{50}\right)\right)+\left(-55.24 \times\left(\mathrm{Z}_{250} / \mathrm{Z}_{5}\right)\right)+\left(-10940 \times\left(1 / \mathrm{Z}_{50}\right)\right)+51.33$ for men, and $\mathrm{ALM}=\left(0.6144 \times\left(\mathrm{Ht}^{2} / \mathrm{Z}_{50}\right)\right)+\left(-36.61 \times\left(\mathrm{Z}_{250} / \mathrm{Z}_{5}\right)\right)+\left(-9332 \times\left(1 / \mathrm{Z}_{50}\right)\right)+37.91$ for women. In the cross validation group, the equation had high determinant coefficients $\left(R^{2}=0.87\right.$ and 0.86 , respectively) with reasonable SEE (1.53 and $1.15 \mathrm{~kg}$ in men and women, respectively). The current study established and validated this theoretical and age-independent equation of MF-BIA for estimating ALM and provided a sarcopenia cutoff value using the equation for the Japanese population. This MF-BIA device is distributed worldwide, thus it is an interesting challenge to develop equations and establish the sarcopenia cut off for various countries with different population as an area of future research. Readers should examine our results and evaluate how they can be interpreted from the perspective of previous studies and the working hypotheses. The current findings and their implications should be discussed in the broadest context possible. Areas for future research may also be identified. 
Acknowledgments: The funding souse of this study was JSPS KAKENHI (15H05363) for Yosuke Yamada.

Author Contributions: All listed authors had full access to all data in the study. Study concept and design: Yosuke Yamada, Miyuki Nishizawa, Yasuhiro Kasahara, Mikio Shindo. Performed analyses: Yosuke Yamada, Miyuki Nishizawa, Tomoka Uchiyama, Yasuhiro Kasahara. Drafting of the manuscript: Yosuke Yamada. Critical revision of the manuscript for important intellectual content: all authors. All of authors approved final manuscript.

Conflicts of Interest: Yosuke Yamada, Motohiko Miyachi, Shigeho Tanaka, and National Institute of Biomedical Innovation, Health and Nutrition did not have any conflict of interest with TANITA Co, i.e., no financial employment, consultancy fees, stock, mutual fund holdings, honoraria, paid expert testimony, family members, research grants, patents, royalties, loans, and gifts from TANITA Co. Co-authors Miyuki Nishizawa, Tomoka Uchiyama, Yasuhiro Kasahara and Mikio Shindo are employed by TANITA Corporation Inc. Performed the measurements of DXA and MFBIA had been done at TANITA Body Weight Scientific Institute, TANITA Co. TANITA have several patents related to BIA, and Yosuke Yamada have two pending patents related to BIA, respectively.

\section{References}

1. World Health Organization. World Report on Ageing and Health; World Health Organization: Genava, Switzerland, 2015.

2. Cabinet Office Japan. Annual Report on the Aging Society; Cabinet Office Japan: Tokyo, Japan, 2016.

3. Yamada, Y.; Nanri, H.; Watanabe, Y.; Yoshida, T.; Yokoyama, K.; Itoi, A.; Date, H.; Yamaguchi, M.; Miyake, M.; Yamagata, E.; et al. Prevalence of frailty assessed by fried and kihon checklist indexes in a prospective cohort study: Design and demographics of the Kyoto-Kameoka longitudinal study. J. Am. Med. Dir. Assoc. 2017. [CrossRef] [PubMed]

4. Janssen, I.; Ross, R. Linking age-related changes in skeletal muscle mass and composition with metabolism and disease. J. Nutr. Health Aging 2005, 9, 408-419. [PubMed]

5. Janssen, I.; Heymsfield, S.B.; Wang, Z.M.; Ross, R. Skeletal muscle mass and distribution in 468 men and women aged 18-88 yr. J. Appl. Physiol. 2000, 89, 81-88. [PubMed]

6. Cruz-Jentoft, A.J.; Landi, F.; Schneider, S.M.; Zúñiga, C.; Arai, H.; Boirie, Y.; Chen, L.K.; Fielding, R.A.; Martin, F.C.; Michel, J.P.; et al. Prevalence of and interventions for sarcopenia in ageing adults: A systematic review. Report of the International Sarcopenia Initiative (EWGSOP and IWGS). Age Ageing 2014, 43, 748-759. [CrossRef] [PubMed]

7. Cruz-Jentoft, A.J.; Baeyens, J.P.; Bauer, J.M.; Boirie, Y.; Cederholm, T.; Landi, F.; Martin, F.C.; Michel, J.P.; Rolland, Y.; Schneider, S.M.; et al. Sarcopenia: European consensus on definition and diagnosis: Report of the European Working Group on Sarcopenia in older people. Age Ageing 2010, 39, 412-423. [CrossRef] [PubMed]

8. Chen, L.K.; Liu, L.K.; Woo, J.; Assantachai, P.; Auyeung, T.W.; Bahyah, K.S.; Chou, M.Y.; Chen, L.Y.; Hsu, P.S.; Krairit, O.; et al. Sarcopenia in Asia: Consensus report of the Asian Working Group for Sarcopenia. J. Am. Med. Dir. Assoc. 2014, 15, 95-101. [CrossRef] [PubMed]

9. Fielding, R.A.; Vellas, B.; Evans, W.J.; Bhasin, S.; Morley, J.E.; Newman, A.B.; van Kan, G.A.; Andrieu, S.; Bauer, J.; Breuille, D.; et al. Sarcopenia: An undiagnosed condition in older adults. Current consensus definition: Prevalence, etiology, and consequences. International working group on Sarcopenia. J. Am. Med. Dir. Assoc. 2011, 12, 249-256. [CrossRef]

10. Yamada, Y.; Masuo, Y.; Yokoyama, K.; Hashii, Y; Ando, S.; Okayama, Y.; Morimoto, T.; Kimura, M.; Oda, S. Proximal electrode placement improves the estimation of body composition in obese and lean elderly during segmental bioelectrical impedance analysis. Eur. J. Appl. Physiol. 2009, 107, 135-144. [CrossRef] [PubMed]

11. Ward, L.C. Segmental bioelectrical impedance analysis: An update. Curr. Opin. Clin. Nutr. Metab. Care 2012, 15, 424-429. [CrossRef] [PubMed]

12. Thomas, B.J.; Ward, L.C.; Cornish, B.H. Bioimpedance spectrometry in the determination of body water compartments: Accuracy and clinical significance. Appl. Radiat. Isot. 1998, 49, 447-455. [CrossRef]

13. Pietrobelli, A.; Tato, L. Body composition measurements: From the past to the future. Acta Paediatr. Suppl. 2005, 94, 8-13. [CrossRef] [PubMed]

14. Organ, L.W.; Bradham, G.B.; Gore, D.T.; Lozier, S.L. Segmental bioelectrical-impedance analysis-Theory and application of a new technique. J. Appl. Physiol. 1994, 77, 98-112. [PubMed]

15. Miyatani, M.; Kanehisa, H.; Masuo, Y.; Ito, M.; Fukunaga, T. Validity of estimating limb muscle volume by bioelectrical impedance. J. Appl. Physiol. 2001, 91, 386-394. [PubMed] 
16. Lukaski, H.C. Applications of bioelectrical impedance analysis: A critical review. Basic Life Sci. 1990, 55, 365-374. [PubMed]

17. Kyle, U.G.; Bosaeus, I.; De Lorenzo, A.D.; Deurenberg, P.; Elia, M.; Gómez, J.M.; Heitmann, B.L.; Kent-Smith, L.; Melchior, J.C.; Pirlich, M.; et al. Bioelectrical impedance analysis—Part I: Review of principles and methods. Clin. Nutr. 2004, 23, 1226-1243. [CrossRef] [PubMed]

18. Kushner, R.F.; Schoeller, D.A. Estimation of total body water by bioelectrical impedance analysis. Am. J. Clin. Nutr. 1986, 44, 417-424. [PubMed]

19. Jaffrin, M.Y.; Morel, H. Body fluid volumes measurements by impedance: A review of bioimpedance spectroscopy (BIS) and bioimpedance analysis (BIA) methods. Med. Eng. Phys. 2008, 30, 1257-1269. [CrossRef] [PubMed]

20. Zhu, F.; Kuhlmann, M.K.; Kaysen, G.A.; Sarkar, S.; Kaitwatcharachai, C.; Khilnani, R.; Stevens, L.; Leonard, E.F.; Wang, J.; Heymsfield, S.; et al. Segment-specific resistivity improves body fluid volume estimates from bioimpedance spectroscopy in hemodialysis patients. J. Appl. Physiol. 2006, 100, 717-724. [CrossRef] [PubMed]

21. Kaysen, G.A.; Zhu, F.; Sarkar, S.; Heymsfield, S.B.; Wong, J.; Kaitwatcharachai, C.; Kuhlmann, M.K.; Levin, N.W. Estimation of total-body and limb muscle mass in hemodialysis patients by using multifrequency bioimpedance spectroscopy. Am. J. Clin. Nutr. 2005, 82, 988-995. [PubMed]

22. Piccoli, A.; Pillon, L.; Dumler, F. Impedance vector distribution by sex, race, body mass index, and age in the United States: Standard reference intervals as bivariate Z scores. Nutrition 2002, 18, 153-167. [CrossRef]

23. De Lorenzo, A.; Andreoli, A.; Matthie, J.; Withers, P. Predicting body cell mass with bioimpedance by using theoretical methods: A technological review. J. Appl. Physiol. 1997, 96, 161-166.

24. De Lorenzo, A.; Andreoli, A. Segmental bioelectrical impedance analysis. Curr. Opin. Clin. Nutr. Metab. Care 2003, 6, 551-555. [CrossRef]

25. Gonzalez, M.C.; Heymsfield, S.B. Bioelectrical impedance analysis for diagnosing sarcopenia and cachexia: What are we really estimating? J. Cachexia Sarcopenia Muscle 2017, 8, 187-189. [CrossRef] [PubMed]

26. Bosy-Westphal, A.; Jensen, B.; Braun, W.; Pourhassan, M.; Gallagher, D.; Müller, M.J. Quantification of whole-body and segmental skeletal muscle mass using phase-sensitive 8-electrode medical bioelectrical impedance devices. Eur. J. Clin. Nutr. 2017. [CrossRef] [PubMed]

27. Bosy-Westphal, A.; Schautz, B.; Later, W.; Kehayias, J.J.; Gallagher, D.; Müller, M.J. What makes a BIA equation unique? Validity of eight-electrode multifrequency BIA to estimate body composition in a healthy adult population. Eur. J. Clin. Nutr. 2013, 67, S14-S21. [CrossRef] [PubMed]

28. Ohta, M.; Midorikawa, T.; Hikihara, Y.; Masuo, Y.; Sakamoto, S.; Torii, S.; Kawakami, Y.; Fukunaga, T.; Kanehisa, H. Validity of segmental bioelectrical impedance analysis for estimating fat-free mass in children including overweight individuals. Appl. Physiol. Nutr. Metab. 2017, 42, 157-165. [CrossRef] [PubMed]

29. Tanaka, N.I.; Hanawa, S.; Murakami, H.; Cao, Z.B.; Tanimoto, M.; Sanada, K.; Miyachi, M. Accuracy of segmental bioelectrical impedance analysis for predicting body composition in pre-and postmenopausal women. J. Clin. Densitom. 2015, 18, 252-259. [CrossRef] [PubMed]

30. Janssen, I.; Heymsfield, S.B.; Baumgartner, R.N.; Ross, R. Estimation of skeletal muscle mass by bioelectrical impedance analysis. J. Appl. Physiol. 2000, 89, 465-471. [PubMed]

31. Mingrone, G.; Bertuzzi, A.; Capristo, E.; Greco, A.V.; Manco, M.; Pietrobelli, A.; Salinari, S.; Heymsfield, S.B. Unreliable use of standard muscle hydration value in obesity. Am. J. Physiol. Endocrinol. Metab. 2001, 280, E365-E371. [PubMed]

32. Yamada, Y.; Schoeller, D.A.; Nakamura, E.; Morimoto, T.; Kimura, M.; Oda, S. Extracellular water may mask actual muscle atrophy during aging. J. Gerontol. Biol. Sci. Med. Sci. 2010, 65, 510-516. [CrossRef] [PubMed]

33. Yamada, Y.; Ikenaga, M.; Takeda, N.; Morimura, K.; Miyoshi, N.; Kiyonaga, A.; Kimura, M.; Higaki, Y.; Tanaka, H. Estimation of thigh muscle cross-sectional area by single-and multi-frequency segmental bioelectrical impedance analysis in elderly. J. Appl. Physiol. 2014, 116, 176-182. [CrossRef] [PubMed]

34. Yamada, Y.; Matsuda, K.; Björkman, M.P.; Kimura, M. Application of segmental bioelectrical impedance spectroscopy to the assessment of skeletal muscle cell mass in elderly men. Geriatr. Gerontol. Int. 2014, 14, 129-134. [CrossRef] [PubMed]

35. Skourou, C.; Rohr, A.; Hoopes, P.J.; Paulsen, K.D. In vivo EIS characterization of tumour tissue properties is dominated by excess extracellular fluid. Phys. Med. Biol. 2007, 52, 347-363. [CrossRef] [PubMed] 
36. Rutkove, S.B. Electrical impedance myography: Background, current state, and future directions. Muscle Nerve 2009, 40, 936-946. [CrossRef] [PubMed]

37. Pichonnaz, C.; Bassin, J.P.; Currat, D.; Martin, E.; Jolles, B.M. Bioimpedance for oedema evaluation after total knee arthroplasty. Physiother. Res. Int. 2013, 18, 140-147. [CrossRef] [PubMed]

38. Yoshida, D.; Shimada, H.; Park, H.; Anan, Y.; Ito, T.; Harada, A.; Suzuki, T. Development of an equation for estimating appendicular skeletal muscle mass in Japanese older adults using bioelectrical impedance analysis. Geriatr. Gerontol. Int. 2014, 14, 851-857. [CrossRef] [PubMed]

39. Yamada, Y.; Yoshida, T.; Yokoyama, K.; Watanabe, Y.; Miyake, M.; Yamagata, E.; Yamada, M.; Kimura, M.; Kyoto-Kameoka Study. The extracellular to intracellular water ratio in upper legs is negatively associated with skeletal muscle strength and gait speed in older people. J. Gerontol. Biol. Sci. Med. Sci. 2017, 72, 293-298. [CrossRef]

40. Yamada, Y.; Watanabe, Y.; Ikenaga, M.; Yokoyama, K.; Yoshida, T.; Morimoto, T.; Kimura, M. Comparison of single-or multifrequency bioelectrical impedance analysis and spectroscopy for assessment of appendicular skeletal muscle in the elderly. J. Appl. Physiol. 2013, 115, 812-818. [CrossRef] [PubMed]

41. Yamada, Y.; Buehring, B.; Krueger, D.; Anderson, R.M.; Schoeller, D.A.; Binkley, N. Electrical properties assessed by bioelectrical impedance spectroscopy as biomarkers of age-related loss of skeletal muscle quantity and quality. J. Gerontol. Biol. Sci. Med. Sci. 2017. [CrossRef]

42. Janssen, I.; Heymsfield, S.B.; Ross, R. Low relative skeletal muscle mass (Sarcopenia) in older persons is associated with functional impairment and physical disability. J. Am. Geriatr. Soc. 2002, 50, 889-896. [CrossRef] [PubMed]

43. Sergi, G.; De Rui, M.; Stubbs, B.; Veronese, N.; Manzato, E. Measurement of lean body mass using bioelectrical impedance analysis: A consideration of the pros and cons. Aging Clin. Exp. Res. 2017. [CrossRef] [PubMed]

44. Kim, M.; Shinkai, S.; Murayama, H.; Mori, S. Comparison of segmental multifrequency bioelectrical impedance analysis with dual-energy $\mathrm{X}$-ray absorptiometry for the assessment of body composition in a community-dwelling older population. Geriatr. Gerontol. Int. 2015, 15, 1013-1022. [CrossRef] [PubMed]

45. Shiose, K.; Yamada, Y.; Motonaga, K.; Sagayama, H.; Higaki, Y.; Tanaka, H.; Takahashi, H. Segmental extracellular and intracellular water distribution and muscle glycogen after 72-h carbohydrate loading using spectroscopic techniques. J. Appl. Physiol. 2016, 121, 205-211. [CrossRef] [PubMed]

46. Sanaada, K.; Miyachi, M.; Tanimoto, M.; Yamamoto, K.; Murakami, H.; Okumura, S.; Gando, Y.; Suzuki, K.; Tabata, I.; Higuchi, M. A cross-sectional study of sarcopenia in Japanese men and women: Reference values and association with cardiovascular risk factors. Eur. J. Appl. Physiol. 2010, 110, 57-65. [CrossRef] [PubMed]

47. Tanimoto, Y.; Watanabe, M.; Sun, W.; Sugiura, Y.; Tsuda, Y.; Kimura, M.; Hayashida, I.; Kusabiraki, T.; Kono, K. Association between sarcopenia and higher-level functional capacity in daily living in community-dwelling elderly subjects in Japan. Arch. Gerontol. Geriatr. 2012, 55, e9-e13. [CrossRef] [PubMed]

48. Yamada, M.; Nishiguchi, S.; Fukutani, N.; Tanigawa, T.; Yukutake, T.; Kayama, H.; Aoyama, T.; Arai, H. Prevalence of sarcopenia in community-dwelling Japanese older adults. J. Am. Med. Dir. Assoc. 2013, 14, 911-915. [CrossRef] [PubMed]

49. Yamada, M.; Yamada, Y.; Arai, H. Comparability of two representative devices for bioelectrical impedance data acquisition. Geriatr. Gerontol. Int. 2016, 16, 1087-1088. [CrossRef] [PubMed]

50. Watanabe, Y.; Yamada, Y.; Fukumoto, Y.; Ishihara, T.; Yokoyama, K.; Yoshida, T.; Miyake, M.; Yamagata, E.; Kimura, M. Echo intensity obtained from ultrasonography images reflecting muscle strength in elderly men. Clin. Interv. Aging 2013, 8, 993-998. [CrossRef] [PubMed]

51. Kent-Braun, J.A.; Ng, A.V.; Young, K. Skeletal muscle contractile and noncontractile components in young and older women and men. J. Appl. Physiol. 2000, 88, 662-668. [PubMed]

52. Goodpaster, B.H.; Carlson, C.L.; Visser, M.; Kelley, D.E.; Scherzinger, A.; Harris, T.B.; Stamm, E.; Newman, A.B. Attenuation of skeletal muscle and strength in the elderly: The Health ABC Study. J. Appl. Physiol. 2001, 90, 2157-2165. [PubMed]

53. Galban, C.J.; Maderwald, S.; Stock, F.; Ladd, M.E. Age-related changes in skeletal muscle as detected by diffusion tensor magnetic resonance imaging. J. Gerontol. Biol. Sci. Med. Sci. 2007, 62, 453-458. [CrossRef]

54. Fukumoto, Y.; Ikezoe, T.; Yamada, Y.; Tsukagoshi, R.; Nakamura, M.; Mori, N.; Kimura, M.; Ichihashi, N. Skeletal muscle quality assessed from echo intensity is associated with muscle strength of middle-aged and elderly persons. Eur. J. Appl. Physiol. 2012, 112, 1519-1525. [CrossRef] [PubMed] 
55. Heymsfield, S.B.; Gonzalez, M.C.; Lu, J.; Jia, G.; Zheng, J. Skeletal muscle mass and quality: Evolution of modern measurement concepts in the context of sarcopenia. Proc. Nutr. Soc. 2015, 74, 355-366. [CrossRef] [PubMed]

56. Ticinesi, A.; Meschi, T.; Narici, M.V.; Lauretani, F.; Maggio, M. Muscle ultrasound and Sarcopenia in older individuals: A clinical perspective. J. Am. Med. Dir. Assoc. 2017, 18, 290-300. [CrossRef] [PubMed]

57. Mitchell, W.K.; Williams, J.; Atherton, P.; Larvin, M.; Lund, J.; Narici, M. Sarcopenia, dynapenia, and the impact of advancing age on human skeletal muscle size and strength; a quantitative review. Front. Physiol. 2012, 3, 260. [CrossRef] [PubMed]

58. Prado, C.M.; Siervo, M.; Mire, E.; Heymsfield, S.B.; Stephan, B.C.; Broyles, S.; Smith, S.R.; Wells, J.C.; Katzmarzyk, P.T. A population-based approach to define body-composition phenotypes. Am. J. Clin. Nutr. 2014, 99, 1369-1377. [CrossRef] [PubMed]

(C) 2017 by the authors. Licensee MDPI, Basel, Switzerland. This article is an open access article distributed under the terms and conditions of the Creative Commons Attribution (CC BY) license (http://creativecommons.org/licenses/by/4.0/). 